\title{
DEMOCRACIA, POLÍTICAS PÚBLICAS E PRÁTICAS EDUCATIVAS REPRESENTADAS NAS PESQUISAS DE EDUCAÇÃO AMBIENTAL SOBRE FORMAÇÃO DE EDUCADORES/PROFESSORES
}

\author{
João Batista de Albuquerque Figueiredo ${ }^{1}$ \\ Laísa Maria Freire ${ }^{2}$
}

\begin{abstract}
Resumo
Este artigo sistematiza trabalhos e discussões promovidas no Grupo de Discussão de Pesquisa (GDP) - Pesquisa em Educação Ambiental e a Formação de Educadores(as) - Professores(as), no IX EPEA. Dialogamos com estudos de Souza-Santos, Freire e Maturana, e com os estudos críticos da linguagem para compreender como democracia, políticas públicas e práticas educativas foram representadas, discursivamente, nos trabalhos do GDP. Foramanalisados os 28 trabalhos submetidos ao GDP. Entendemos que a pesquisa engajada está presente nas preocupações e motivações dos pesquisadores do GDP. Isso gera cenários empíricos diversos para análise das práticas educativas, em geral provindas de contextos locais. Além disso, observamos nesse GDP que as políticas públicas têm representado uma fonte de problematização, de questões, por sua vez, gerando pautas de novas pesquisas.Realizamos presencialmente um círculo dialógico, nos moldes de Paulo Freire. Nele, o grupo sinalizou para o entendimento dos limites da formação, diante desse quadro atual e, particularmente diante de uma democracia que não nos representa e uma formação institucionalista, imposta de cima para baixo, proposta de uma maneira artificial e dissociada do ambiente a que se destina, desconhecedora do grupo ao qual é proposta, em geral. Ao final, propomos uma agenda de pesquisa para o GDP.
\end{abstract}

Palavras-chave: Formação de Educadores ambientais. Democracia Representativa. Políticas Públicas.

\section{DEMOCRACY, PUBLIC POLICIES AND EDUCATIONAL PRACTICES REPRESENTED IN ENVIRONMENTAL EDUCATION RESEARCH ON TEACHER EDUCATION}

\begin{abstract}
In this paper we systematize papers and discussions held in the Discussion Research Group (DRG) - Environmental Education Research and the Formation of Educators - Teachers, in the IX EPEA. We debate with Souza-Santos, Freire and Maturanaand with the critical language studies to characterize how democracy, public policies and educative practiceswas discursive represented in the analysed papers. We analysed 28 papers from DRP. We understand that engaged research is present in the concerns and motivations of the DRG researchers. This generates several empirical scenarios for analyzing educational practices, usually from local contexts. In addition, we observed in this DRG that public policies have represented a source of problematization, of questions, in turn, generating new research guidelines.We conducted a dialogical circle as Paulo Freire's theoretical framework. During

\footnotetext{
1 Professor Associado da Faculdade de Educação e do Programa de Pós-Graduação em Educação da Universidade Federal do Ceará. Líder do Gead. Mestre em Saúde Pública. Doutor em Ciências (UFSCar) com Pós-doutorado em Educação (UFSC e UFF). <joaofigueiredo@ hotmail.com>.

${ }^{2}$ Bióloga, Mestra em Ciências e Doutora em Educação em Ciências e Saúde, Professora Adjunta, Programa de Pós-graduação em Educação em Ciências e Saúde, NUTES, Programa de Pós-graduação em Ciências Ambientais, NUPEM, Universidade Federal do Rio de Janeiro, Brasil, Departamento de Ecologia.<laisa@biologia.ufrj.br>.
} 
de dialogical circle, the group signalled for the understanding of the limits of formation, in regards to the current situation, in particular a democracy that does not represent an institutionalized education, and that was imposed top-down, in an artificial and dissociated way to the environment it is destined, unaware of the group to which it is proposed, in general. At the end we finish with a research agenda for DRG.

Keywords: Formation of environmental educators. Representative Democracy. Public policy.

\section{DEMOCRACIA, POLÍTICAS PÚBLICAS Y PRÁCTICAS EDUCATIVAS REPRESENTADAS EN LAS INVESTIGACIONES DE EDUCACIÓN AMBIENTAL SOBRE FORMACIÓN DE EDUCADORES / PROFESORES}

\section{Resumen}

Este artículo sistematiza trabajos y discusiones promovidas en el Grupo de discusión de Investigación (GDI) - Investigación en Educación Ambiental y la Formación de Profesoresy Educadores, en el IX EPEA. Utilizamos estudios de Souza-Santos, Freire y Maturana y estudios críticos del lenguaje para comprender como democracia, políticas públicas y prácticas educativas fueron representadas discursivamente en los trabajos del GDI. Se analizaron los 28 trabajos sometidos al GDI. Entendemos que la investigación comprometida con la práctica está presente en las preocupaciones y motivaciones de los investigadores del GDI. Esto genera escenarios empíricos diversos para el análisis de las prácticas educativas, en general provenientes de contextos locales. Además, observamos en este GDI que las políticas públicas han representado una fuente de problematización de cuestiones, a su vez, generando pautas de nuevas investigaciones. Realizamos presencialmente un círculo dialógico, en los moldes de Paulo Freire. En él, el grupo señaló para el entendimiento de los límites de la formación, frente a un cuadro actual y particularmente ante una democracia que no nos representa y una formación institucionalista, impuesta de arriba abajo, propuesta de una manera artificial y disociada del ambiente a que se destina, desconocedora del grupo al que se propone. Al final, proponemos una agenda de investigación para el GDI.

Palabras clave: Formación de Educadores ambientales. Democracia Representativa. Políticas públicas.

\section{Introdução}

O Grupo de Discussão de Pesquisa (GDP) de formação de educadores/professores vem, a cada Encontro de Pesquisa em Educação Ambiental - EPEA, sendo responsável por um número mais expressivo de trabalhos apresentados no evento. "Os GDP foram propostos a partir do III EPEA, em 2005, como uma nova modalidade para a discussão, em grupos, das pesquisas apresentadas no evento" (CARVALHO, 2016, p.151). O GDP de formação de educadores/professores iniciou-se em 2007, no IV EPEA (CARVALHO, 2016). Na edição do IX EPEA foram 28 dos 117 trabalhos que constam nos anais do evento ${ }^{3}$.

Temos observado uma preocupação crescente com a questão da identidade do educador ambiental, com a formação e lugares de formação, tanto em termos de trabalhos submetidos quanto em número de pessoas que têm participado das discussões durante as edições do evento. Freire, Figueiredo e Guimarães (2016), ao relatarem o GDP de formação de educadores/professores do VIII EPEA, entendem que a identidade do educador ambiental deve ser vislumbrada para além da formação inicial disciplinar, e que tal processo formativo

${ }^{3}$ Disponíveis em: <(http://epea.tmp.br/epea2017_anais/list/)> 
pode se constituir em espaços alternativos dentro do currículo da própria formação superior. Consideram a legitimação de espaços de formação do educador ambiental na universidade, como PIBID, programas de Extensão e Grupos de Estudos e Pesquisas, como caminhos possíveis e ressaltam a importância de "uma formação crítica e dialógica, que se propõe a reconhecer o(a) educador(a) ambiental em formação como autor(a) de sua própria formação e de sua trajetória como alguém que elabora seu próprio conhecer na relação com outros seres." (FREIRE; FIGUEIREDO; GUIMARÃES, 2016, p.117)

No presente trabalho, buscamos aprofundar e ampliar as discussões desse GDP. Para a ampliação dessa discussão, estabelecemos possíveis relações com o tema geral da nona edição do evento, principalmente em virtude de sua pertinência temporal. No sentido de aprofundamento, optamos por realizar análises discursivas dos trabalhos submetidos a esse GDP. Inspirados pelos estudos críticos da linguagem, por uma abordagem crítico-dialógica, buscamos compreender como democracia, políticas públicas e práticas educativas foram representadas, discursivamente, nos trabalhos do Grupo de Pesquisa de formação de educadores/professores. Como delimitação da prática social, caracterizamos a pesquisa em educação ambiental como prática social e o GDP de formação do IX EPEA como um evento que se insere nessa prática. Analisamos, com recortes, os 28 textos submetidos ao GDP no percurso proposto a seguir.

Na seção 2 deste artigo, iniciamos com uma breve caraterização da conjuntura definida pelo tema geral do evento e do quadro teórico que orienta a análise. Em seguida, apresentamos os caminhos metodológicos e uma caracterização geral dos trabalhos do GDP. Apresentamos as análises e discutimos que, de modo geral, os trabalhos marcam seu espaço de identidade, situando-se nos aspectos da EA crítica, ainda que a representem de modo distinto. Caracterizamos que a discussão sobre a formação dos educadores(as)/professores(as) é situada a partir de demandas das políticas públicas, ou seja, de uma legislação que orienta e regula a educação ambiental na formação docente e que estas, as políticas públicas, também geram problemas de pesquisa e formação, não necessariamente questões teóricas e/ou de lacunas do conhecimento. Assim, os espaços educativos, como espaços de prática, são representados por maior ou menor resposta às demandas das políticas públicas orientadoras de uma formação do educador. Esses espaços e lugares da prática são o foco privilegiado das pesquisas anunciadas nesse GDP. Ao final, propomos uma agenda de pesquisa para o Grupo de Pesquisa - GDP.

\section{Democracia, políticas públicas e práticas educativas}

A edição do IX EPEA teve como tema democracia, políticas públicas e práticas educativas. Esse tema foi amplamente debatido a partir do momento histórico que vivemos na atualidade, caracterizando uma série de perdas democráticas em nossa sociedade. Sem entrar em definições sobre democracia, estamos privilegiando um sentido de democracia que, na sua relação com a EA, se faz por meio da participação coletiva nos espaços de tomada de decisão e promoção de políticas públicas para a gestão do meio. Claro que, nesse processo, se considera e se entende que os espaços democráticos não são dados a priori, ao contrário, são carregados de lutas e conflitos. Assim, o processo democrático envolve instaurar acordos entre os agentes sociais, por meio da participação, do debate, do diálogo, do exercício e da construção de uma cidadania. No site do evento, a justificativa para o tema encontra-se apresentada do seguinte modo:

[...] a IX edição, cuja temática é "Pesquisa em educação Ambiental: democracia, políticas públicas e práticas educativas", que toma forma a partir da relação entre educação ambiental e democracia, considerando as questões contemporâneas que atravessam tal relação e que encontram acolhida em diversos grupos de pesquisas do campo. Compreendemos que vivemos tempos assolados por uma cultura de 
violências, relacionadas a violações de direitos ambientais e humanos. São violências que permeiam nossas subjetividades, nossas formas de ser, pensar, agir, e que muitas vezes se apresentam sob forma de investigações de distintas naturezas, sem que se leve em conta seus significados e implicações, sobretudo às políticas públicas e às práticas educativas(EPEA, 2017, s/p).

Para Loureiro e Cunha (2008, p.242), o educador ambiental tem o desafio de trabalhar para a "superação das relações sociais vigentes, na conformação de uma ética que possa se afirmar como "ecológica" e na objetivação de um patamar societário que seja a expressão da ruptura com os padrões dominadores e de expropriação que caracterizam a contemporaneidade". Nesse sentido, as políticas públicas e as práticas educativas podem contribuir à superação de hegemonias. Elas o farão quando construídas no debate, no diálogo ou no embate e a partir das suas implicações no campo da pesquisa em EA. Ainda no sitedoevento, o enunciado do objetivo explica que o mesmo se caracteriza enquanto espaço de debate e de formação, comprometido "com o direito ao reconhecimento, a participação social, a distribuição igualitária de bens, serviços sociais, ambientais, econômicos, culturais e políticos e ao fortalecimento do Estado Democrático de Direito" (EPEA, 2017, s/p).

No trato da temática relativa às políticas públicas, precisamos ter em conta que para muitos estudiosos dessa temática, políticas podem ser entendidas como um conjunto de ações coletivas voltadas para a garantia dos direitos sociais (FIGUEIREDO, 2010). Estas configurariam um compromisso público para atender determinada demanda social (GUARESCHI et al., 2004).

Por outro lado, no dicionário Aurélio, Políticas Públicas designam certo tipo de orientação para a tomada de decisões em assuntos públicos, políticos ou coletivos (FERREIRA,1999). Entendemos que, em geral, as políticas públicas estão relacionadas com questões fundamentais, tais como: liberdade e igualdade, direito à satisfação das necessidades básicas, emprego, educação, saúde, habitação, acesso à terra, meio ambiente, transporte etc. Portanto, políticas públicas compreenderiam ações e procedimentos com o propósito da resolução pacífica de conflitos em torno da alocação de bens e recursos públicos. Na prática, porém, o que se observa concretamente é que a regra se dá em torno do atendimento de demandas decorrentes das elites em detrimento das reais necessidades populares.

Apoiados em Boaventura de Sousa Santos (2008), Humberto Maturana (1993, 1998), Paulo Freire (1983), somos levados a reconhecer que o modo de operar essas proposições e a constituição das políticas públicas se associam às dimensões constitutivas dos saberes modernos que justificam, ou asseguram as justificativas, para argumentar em favor da proposta de políticas que se dizem públicas, mas que atendem às pretensões empresariais ou de grandes corporações com forte poder de barganha e/ou contratação de laudos e estudos que afirmam os interesses desses que definem as políticas públicas, que, por sua vez, definem recursos e investimentos de largo vulto, beneficiando segmentos sociais privilegiados.

Num pequeno parêntese que confirma a regra, trazemos um arrazoado de Santos (2008), ao caracterizar a modernidade ocidental. Para este, a sociedade moderna se funda sobre um paradigma constituído pela tensão entre regulação e emancipação social. Ele reforça seu entendimento de que as políticas e legislações que atuam na regulação ao serem pensadas no sentido de manutenção do status dominante. Santos (2008), ao tratar dos direitos humanos, destaca que a política se revela como cultura política resultante do embate entre as monoculturas hegemônicas e as aspirações interculturais, contra-hegemônicas.

É nesse entremeio que podemos reconhecer a relevância de propostas que se disponham a enfrentar um paradigma epistemológico assentado nesse modelo de racionalidade instrumental, cartesiana, pragmática, mercantil, colonializante. Parece-nos central a questão do desvelamento da racionalidade moderna e desse enfrentamento na perspectiva de garantir a emancipação com fins de configurar outro espaço para a elaboração de conhecimento, 
distintas maneiras de pensar e novas leituras de mundo. Com isso, viabilizar epistemologias plurais ou populares como possibilidade (FIGUEIREDO, 2010).

Nessa direção, a garantia de alternativas que se contraponham ao modelo hegemônico de formação docente favoreceria o advento de possibilidades superadoras da subalternidade e da colonialidade dominante. $\mathrm{E}$ isso se torna factível através de políticas públicas que contemplem essas outras demandas, mais consentâneas com a realidade. Como tais estratégias poderiam impregnar nossas pesquisas? Que compromissos tem a educação ambiental com alternativas de formação?

Temos clara a ideia de que garantir formações docentes identificadas com os contextos sociais portadores de situações de risco, carências sócio-eco-ambientais, fazem verdadeiro sentido na perspectiva de propostas integradas ao mundo real. Reafirmando o apresentado, a partir do tema da democracia, Maturana (1993), enfatiza que precisamos ter ciência de que essas questões são atravessadas pela cultura. Ele nos recorda que nossa democracia funciona dentro de uma lógica identificada com a cultura patriarcal, na qual a democracia ocidental moderna surgiu. Cultura belicosa, autoritária, controladora - em particular da sexualidade-, machista, imperialista, capitalista, hierarquizante, competitiva, mercadológica.

Bem, ao reconhecermos de que somos filhos do nosso tempo, dessa cultura, constatamos que nossa humanidade se constitui na linguagem, marcada e forjada pelo emocionar. Humberto Maturana (1993) salienta que o humano é forjado na linguagem e na emoção. Em suas palavras, a linguagem é a coordenação de coordenações comportamentais. Nos recorda, ainda, que conversar significa versar - girar ao redor - junto com... e é nessa companhia que podemos fazer a diferença, fazer diferente. Essa é a nossa expectativa de que podemos transformar essa configuração social atual na direção de um mundo mais solidário.

\section{Estudos críticos do discurso como inspiração teórico-metodológica}

Utilizamos os estudos críticos do discurso, ancorados na formulação de Norman Fairclough (2003) para um diálogo com os textos do GDP. Estes trazem a possibilidade de entender uma prática social a partir do seu momento discursivo. Isso porque o quadro teórico permite relacionar a linguagem com questões sociais, buscando os níveis macro da sociedade ou das teorias sociais para explicar os fenômenos analisados.

Assim, a proposta da análise crítica do discurso (ACD) é que, através da análise de amostras localizadas discursivamente (textos falados ou escritos), se torna possível entender como os discursos (a linguagem em uso) são construídos nas relações com seus contextos macrossociais de existência (estruturas), como os discursos se transformam e, assim, conformam suas próprias práticas sociais, ainda que ressalvadas as incongruências e incoerências das práticas sociais. O quadro tem uma proposta comprometida politicamente com as discussões acerca das relações de poder e desigualdades entre as estruturas e eventos que se relacionam dialeticamente, constituindo a prática social.

Para a ACD, as práticas sociais resultam da articulação de diferentes elementos, tais como relações sociais, crenças, atitudes, mundo material e discurso, que são caracterizados por momentos da prática social. As práticas sociais podem ser entendidas como modos habituais compartilhados, vinculados a tempos e espaços em que sujeitos investem recursos materiais e/ou simbólicos para agir no mundo (CHOULIARAKI; FAIRCLOUGH, 1999).

Estamos considerando a pesquisa em educação ambiental como uma prática social. Fairclough (2003) traça a relação entre eventos sociais, práticas sociais e estrutura social, que constitui o nível macrossocial. As estruturas são mais abstratas, podem ser entendidas como o que possibilita e constrange a ação humana, assim como o que resulta dela, a transformação social passa pela transformação das estruturas. Como reflexão, poderíamos pensar sobre que estruturas têm regulado a pesquisa em educação ambiental? 
A nível micro, a linguagem possibilita a produção dos textos pelos atores sociais. Os textos, falados ou escritos, são partes dos eventos sociais, pois têm a primazia de gerarem efeitos, ao ponto de alterar os conhecimentos, as crenças, as atitudes e os valores (FAIRCLOUGH, 2003), podendo acarretar mudanças no nosso conhecimento e na estrutura social. No nosso caso, estamos considerando o GDP do IX EPEA como um evento social em que dois tipos de textos foram produzidos, os previamente submetidos ao IX EPEA - os trabalhos completos - e os textos produzidos durante o debate no GDP nos dias do IX EPEA.

Partimos da noção de interdiscursividade dos estudos críticos da linguagem, considerando que todo texto dialoga com textos anteriores, responde e antecipa determinadas questões, configurando uma cadeia de enunciados. Os textos dos trabalhos submetidos ao congresso foram escritos com a intenção de divulgação de pesquisas no campo da educação ambiental, e, para isso, precisaram responder a formatos e conteúdos demandados pelo encontro, que, por sua vez, portam uma certa estabilidade com as demandas de eventos outros nas áreas de humanas. Nesse sentido, são aceitos pelo encontro de pesquisa em educação ambiental, relatos de pesquisa e ensaios teóricos. Essas regras para os textos são apresentadas aos pesquisadores que querem participar do congresso no momento de divulgação do encontro e sua agenda (através de uma circular ou chamada) que é divulgada para a comunidade científica da área e/ou áreas afins.

Os trabalhos, como respostas discursivas, dialogam com o evento em si, mas, também, com o campo da pesquisa em educação ambiental que define o que pode ou não ser aceito como pesquisa. Assim, consideramos que as relações dialógicas que podemos estabelecer a partir da análise dos trabalhos podem informar sobre a prática da pesquisa em educação ambiental e sobre a prática no EPEA e, mais especificamente, ao evento desse GDP.

Para este trabalho, utilizamos alguns aspectos da ACD para entender como os trabalhos aceitos no EPEA representam e configuram as questões apresentadas anteriormente no campo de pesquisa em educação ambiental, como prática social. Assim, o quadro teóricometodológico da ACD permite entender que a produção dos textos pelos autores não é plenamente livre. Portanto, a ACD permite "mapear conexões entre escolhas de atores sociais ou grupos, em textos e eventos discursivos específicos, e questões mais amplas, de cunho social, envolvendo poder" (RAMALHO; RESENDE, 2011, p. 21). O termo ordens do discurso nos ajuda a analisar essa produção. Corresponde ao momento discursivo da prática social, caracterizado por três dimensões: gênero, discurso e estilo. Ramalho e Resende (2011, p.47), a partir dos estudos de Chouliaraki e Fairclough (1999), consideram "gêneros, 'tipos de linguagem ligados a uma atividade social particular', discursos, 'tipo de linguagem usado para construir algum aspecto da realidade de uma perspectiva particular', e estilos, 'tipo de linguagem usado por uma categoria particular de pessoas e relacionado com sua identidade' ".

\section{Uma visão geral dos trabalhos a partir do diálogo com os estudos críticos do discurso}

Dos 28 trabalhos, caracterizamos: um ensaio teórico sobre valores da EA na formação continuada de educadores e 27 relatos de pesquisa. Assim, nas modalidades previstas pelo EPEA, a de relatos de pesquisa foi a mais expressiva no GDP. Destes 27, sete eram do tipo estado da arte, que apresentavam a discussão sobre formação e/ou questões afins a partir de levantamentos e análises de eventos como o próprio EPEA, ANPEd, e teses e dissertações por meio do banco de dados. Os trabalhos de estado da arte se configuram como pesquisas sobre as pesquisas no campo da EA, constituindo importante meio para entender a prática da pesquisa em EA no Brasil. Contudo, neste trabalho optamos por não analisar as representações discursivas dos trabalhos tipo estado da arte. 
Os 28 trabalhos do GDP têm 71 autores no total, representando um corpo de pesquisadores do campo. Havia um trabalho da Colômbia e os demais foram produção nacional. Em termos de distribuição dos autores por estado, onze trabalhos envolveram autores de São Paulo, das universidades UNESP, USP, UNINOVE. Seis trabalhos envolveram autores vinculados a instituições no Estado de Minas Gerais como a UFJF, Colégio Pedro II, UFT e UEMG. Vinculados a instituições no estado do Espírito Santo, encontramos dois trabalhos. Já no Rio de Janeiro, cinco trabalhos envolveram autores das instituições UERJ, UFRJ, UFRRJ, Fiocruz e PUC-Rio. Do total de trabalhos, observamos, em dois deles, autorias compartilhadas com professores de escolas municipais e estaduais.

Nos 28 trabalhos do GDP encontramos 39 citações e referências a trabalhos internacionais, sem considerar as referências aos autores com seus trabalhos traduzidos, como Vygotsky, Bakhtin, Enrique Leff, entre outros. Ao mesmo tempo em que desenvolvemos a pesquisa engajada, ou seja, comprometida com contextos e situações locais, as pressões e políticas de internacionalização das pesquisas se fazem presentes, com questões globais que regulam e configuram discursos de avaliação (na pós-graduação, por exemplo) e de qualidade das próprias pesquisas. Nesse sentido, encontramos diálogos, ainda incipientes, com uma literatura internacional do campo da educação ambiental, mesmo considerando os diálogos latino-americanos que poderiam ser caracterizados como afins ideologicamente por questões de lutas e embates do sul.

Autores como Souza-Santos (2011) apostam em uma geoepistemologia do Sul, em busca de processos de emancipação do capitalismo e do colonialismo. Assim, ele reconhece que, no nível latino-americano, há uma maior visibilidade das lutas sociais voltadas para a ressignificação de conceitos antigos e a introdução de novos, que não fizeram parte da teoria crítica eurocêntrica, o que implica assimilar que a compreensão do mundo, e, no nosso caso, da pesquisa, não é só ocidental, pois há uma diversidade de ser, pensar, sentir, nos modos de se relacionar, entre outros, que leva a uma significação de mundo distinta.

A análise das representações discursivas foi realizada em alguns dos trabalhos do GDP, a partir de recortes da pesquisa. Considerando que os trabalhos completos enviados têm uma estrutura de gênero que se aproxima do artigo científico, optamos por analisar os resumos dos trabalhos empíricos com foco na prática educativa (vinte trabalhos dos 28 do GDP) - pressupondo que os elementos centrais e considerados como importantes para o trabalho estariam explicitados nos resumos.

Assim, selecionamos os resumos que faziam menção às políticas públicas. O recorte da pesquisa se justifica, uma vez que, inicialmente, buscamos caracterizar os resumos nos quais os termos democracia e que apresentassem uma caracterização de práticas educativas também estivessem presentes. Contudo, esses termos/práticas não se mostraram adequados para o recorte, uma vez que nenhum trabalho apresentou, no resumo, a palavra democracia e, por outro lado, todos os trabalhos empíricos com foco na prática educativa, mencionavam o contexto educativo da pesquisa.

Ainda assim, encontramos três trabalhos que atendiam nossa pretensão inicial. Fizemos uma análise mais detalhada deles. Analisamos como políticas públicas e práticas educativas foram representadas discursivamente. Nas análises, buscamos relacionar as palavras (verbos, conectores), utilizadas para a caracterização das políticas públicas e das práticas educativas, bem como suas relações semânticas. Nos resultados esses trabalhos são citados conforme autor e ano.

O quadro a seguir apresenta a caracterização dos trabalhos analisados discursivamente. A estrutura é apresentada da forma como estava em cada subtítulo. A estrutura dos trabalhos segue um padrão regulado pelo EPEA e presente na pesquisa em educação ambiental. Todos os trabalhos analisados apresentam figuras, gráficos, quadros e/ou tabelas na seção de resultados. 


\begin{tabular}{|c|c|c|c|}
\hline Autores & Título & $\begin{array}{l}\text { Número } \\
\text { de } \\
\text { páginas }\end{array}$ & Estrutura \\
\hline $\begin{array}{ll}\text { Farias } & \mathrm{e} \\
\text { Martorano } & \end{array}$ & $\begin{array}{l}\text { O desafio das questões } \\
\text { étnico-raciais e a } \\
\text { educação ambiental na } \\
\text { formação de professores: } \\
\text { um estudo de caso }\end{array}$ & $\begin{array}{l}8 \\
\text { páginas }\end{array}$ & $\begin{array}{l}\text { Resumo, palavras-chave, abstract, } \\
\text { keywords, introdução, } \\
\text { metodologia, resultados e } \\
\text { discussão, conclusões, referências } \\
\text { bibliográficas }\end{array}$ \\
\hline $\begin{array}{l}\text { Garrido } \\
\text { Meirelles }\end{array}$ & $\begin{array}{l}\text { Educação Ambiental na } \\
\text { formação Docente: o que } \\
\text { discutir? }\end{array}$ & $\begin{array}{l}10 \\
\text { páginas }\end{array}$ & $\begin{array}{l}\text { Resumo, palavras-chave, abstract, } \\
\text { keywords, introdução, } \\
\text { fundamentação teórica, caminho } \\
\text { metodológico, resultados e } \\
\text { discussão, considerações finais, } \\
\text { referências }\end{array}$ \\
\hline $\begin{array}{l}\text { Notalgia como e } \\
\text { Carvalho }\end{array}$ & $\begin{array}{l}\text { O currículo paulista e as } \\
\text { abordagens da relação } \\
\text { homem natureza }\end{array}$ & $\begin{array}{l}9 \\
\text { páginas }\end{array}$ & $\begin{array}{lr}\text { Resumo, palavras-chave, abstract, } \\
\text { keywords, introdução, objetivos e } \\
\text { justificativa, } \\
\text { específicos, } \\
\text { resultadotivos } \\
\text { referências }\end{array}$ \\
\hline
\end{tabular}

Quadro 1 - Caracterização quanto à estrutura dos trabalhos submetidos aos GDP de formação de professores/educadores no IX EPEA

Segundo Pereira, Basílio e Leitão (2017, p.674), por artigo científico, como gênero textual, se entende que:

[...] o artigo científico constitui-se, na atualidade, um dos gêneros textuais mais recrutados na divulgação dos resultados de pesquisas científicas. Fato, provavelmente, motivado por três características básicas: tamanho reduzido, caráter completo e diversidade e atualidade do conteúdo difundido (cf.: Marconi e Lakatos 2003: 259); e também pela ampliação do número de periódicos especializados que circulam em âmbito nacional e internacional que se disponibilizam a publicá-lo.

Contudo, para a ADC, gêneros não são tipos textuais fixos, mas, sim, um dos momentos de ordens do discurso, daí serem definidos como gêneros discursivos, e não gêneros textuais, como explicam Ramalho e Resende (2011). Sobre a caracterização do artigo cientifico como gênero discursivo, Chouliaraki\&Fairclough (1999, p. 144) reconhecem nos gêneros discursivos "um mecanismo articulatório que controla o que pode ser usado e em que ordem, incluindo configuração e ordenação de discursos". Reconhecemos, nos trabalhos analisados, elementos que compõem um artigo científico, embora a finalidade do evento não seja a publicação dos trabalhos em periódicos, e, sim, nos anais do EPEA. Nesse caso, para o evento são aceitos estudos em andamento (não tendo o caráter completo mencionado na citação de Pereira, Basílio e Leitão (2017) e quem regula o que pode ou não ser aceito é a organização geral do evento.

\section{A discussão da formação a partir das políticas públicas de Educação Ambiental}

Nos trabalhos do GDP as políticas públicas representadas foram: (i) políticas específicas de EA como a Política Nacional de EA, o Decreto 4.281 que a regulamenta, o Programa Nacional de EA e as Diretrizes Curriculares Nacionais para a EA; (ii) políticas de educação, como as Diretrizes Curriculares Nacionais para a Escola Básica, Diretrizes Curriculares Nacionais para a formação de professores, a Lei de Diretrizes e Bases para a Educação, os 
Parâmetros Curriculares Nacionais, e a proposta preliminar da Base Nacional Comum Curricular e as políticas de Meio Ambiente, representadas como a lei 6.938, Convenção sobre diversidade biológica, além da Constituição Federal com referência ao artigo 225, que trata do direito ao meio ambiente ecologicamente equilibrado.

Outras, mais específicas, como Política de Proteção e Defesa Civil e Programa Nacional de Educação na Reforma Agrária também foram encontradas. Essas políticas estavam mencionadas nas referências dos trabalhos do GDP e elas aparecem em três trabalhos, nos resumos e na fundamentação do problema de investigação. Para esses trabalhos, as políticas públicas servem como orientação e problematização da necessidade de investir na formação do docente/educador ambiental. Nesse sentido, a legislação serve como uma orientação global para as práticas educativas nos contextos locais. Nesses trabalhos, a prática social da pesquisa em EA é gerada por inquietudes de entendimento das práticas educativas à luz do que é preconizado pelas políticas sem necessariamente questioná-las ou entendê-las a partir dos seus contextos de produção.

O trabalho de Farias e Martorano (2017) inicia a discussão das políticas públicas, ressaltando que o debate do projeto de lei da Escola sem partido poderá comprometer as políticas vigentes (leis 11.645/08 e 9.795/99), como quando tratam da transversalidade de ensino das questões etnicorraciais e educação ambiental, e defende que temas como as práticas religiosas da Umbanda e do Candomblé sejam vivenciadas no espaço escolar. O substantivo utilizado no texto - atendimento - ressalta a premissa da investigação quanto ao desenvolvimento de uma prática educativa que atenda à legislação. Nesse sentido, dada a problematização feita na pesquisa e às ameaças à democracia, frente ao que poderia vir com o projeto de lei da Escola sem partido, atender à legislação vigente seria garantir a possibilidade de resistência de determinadas práticas. Essa discussão é retomada no item de conclusão do trabalho, no qual os autores também citam o Programa Nacional de Educação Ambiental (ProNEA) (BRASIL, 2005 apud FARIAS; MARTORANO, 2017) como promotor de uma ética ecológica.

O trabalho de Garrido e Meirelles (2017) tem sua introdução a partir da problematização das políticas públicas que orientam a inserção da EA nas diferentes modalidades de ensino. Traz, além das políticas, o debate na literatura sobre essa inserção. No texto das autoras, verbos como orientar e dever caracterizam as políticas públicas de Educação Ambiental, como orientadoras das práticas educativas. O advérbio conectivo entretanto, o substantivo problema e termos como poucos se preocupam caracterizam os limites das práticas educativas à luz do debate da literatura no campo da EA.

Nas seções de resultados e conclusões as políticas públicas também aparecem representadas. Nos resultados, o texto traz uma citação de um pesquisador do campo, afirmando que a educação ambiental não é uma política pública consolidada, e as autoras atribuem esse fato à diferença entre o que é proposto na teoria - por meio das políticas - e o que ocorre na prática. $\mathrm{O}$ advérbio conectivo portanto é utilizado na construção da relação entre as orações e traduz uma ideia de consequência/causalidade. Nas considerações finais as políticas públicas voltam a ser mencionadas e são citados os Parâmetros Curriculares Nacionais - PCNs (BRASIL, 1997 apud GARRIDO; MEIRELLES, 2017) e a proposta da Base Nacional Comum Curricular - BNCC (2016) considerando que o trabalho proposto pode contribuir para o alcance do que é preconizado pelas políticas. No texto não foram representadas as divergências ideológicas entre as duas políticas citadas.

Também no trabalho de Notalgiacomo e Carvalho (2017), as políticas públicas de EA são representadas como um desafio ao educador ambiental, ao preconizar a interdisciplinaridade da EA. As autoras consideram que a Política Nacional de Educação Ambiental - PNEA (BRASIL, 1999 apud NOTALGIACOMO; CARVALHO, 2017) fortalece o debate acadêmico ao demandar a interdisciplinaridade nas práticas educativas. Elas 
analisam no currículo paulista as situações de aprendizagem que abordam a temática ser humano-natureza, e observam lacunas nos materiais analisados, fornecidos pela própria Secretaria Estadual. Na visão das autoras, a Secretaria teria a função de executar e fomentar a política pública.

\section{As práticas educativas de formação representadas no GDP de formação de professores/educadores}

Foram representadas práticas educativas de formação inicial e continuada, alguns trabalhos ressaltaram que as práticas educativas estão relacionadas a projetos de pesquisa que tem interface com projetos de extensão universitária, bem como a partir de experiências do PIBID. Os trabalhos de pesquisa sobre a formação continuada, que representam discursivamente os contextos de cursos, buscam a inovação pedagógica, assumindo que o novo permite superar visões reducionistas de EA que não compreendem o ser humano como ser histórico e determinado por relações sociais.

Nesse sentido, trabalhos caracterizam a formação continuada docente propondo e analisando novas alternativas metodológicas (estudo de caso pedagógico, trilha etc.) e abordagens pedagógicas (como controvérsias sociocientíficas, trabalho a partir da interdisciplinaridade) para a inserção da EA na prática docente e escolar. Os trabalhos que discutem a formação inicial utilizam diferentes contextos e diferentes licenciaturas. A licenciatura em Ciências Biológicas é a mais representada, mas também há trabalhos que retratam práticas educativas nas licenciaturas em Química e Pedagogia.

Foram observadas, nos textos, relações semânticas em nível mais alto entre seções do texto, por exemplo, problematização na introdução que apresenta um problema e a estrutura da investigação que gera uma solução para o problema da prática educativa. No trabalho de Farias e Martorano (2017) a formação inicial de professores de ciências foi discutida a partir de experiências dentro de uma disciplina - Mirongas Ambientais e, foi esta a disciplina que, ao ser desenvolvida, pode desencadear a superação dos problemas da prática educativa enunciados no trabalho, tais como a promoção e o respeito à sociodiversidade,

Garrido e Meirelles (2017), ao levantarem temas para tratamento didático da educação ambiental com estudantes de pedagogia e licenciandos de Ciências Biológicas, caracterizam potencialidades e limites para uma formação crítica do professor/pedagogo.

Dos trabalhos analisados em profundidade, Garrido e Meirelles (2017) e Farias e Martorano (2017) citam como referencial teórico a educação ambiental crítica. Fazem proposições afirmativas e citam autores que a caracterizam. O trabalho de Notalgiacomo e Carvalho (2017) argumenta quanto ao desenvolvimento de práticas educativas críticas, definindo explicitamente uma identidade com essa macrotendência. Nesse sentido, os trabalhos marcam diferença com outros que não dialogam com os referenciais críticos da educação ambiental. Assim, defendem, na pesquisa engajada, pressupostos críticos para o processo de formação nas práticas educativas que desenvolvem.

Podemos afirmar que, de modo geral, os trabalhos assumem seu espaço de identidade situando-se nos aspectos da EA crítica, ainda que a representem de modo distinto. Para Notalgiacomo e Carvalho (2017), a educação ambiental crítica articula conhecimento, intencionalidade e transformação social. Garrido e Meirelles (2017) representam a educação ambiental por meio de citações de autores do campo e consideram a complexidade presente nas relações entre ser humano, sociedade, educação e natureza. A questão da interdisciplinaridade aparece como uma prática educativa crítica em educação ambiental, nos trabalhos de Garrido e Meirelles (2017) e de Notalgiacomo e Carvalho (2017). 
Relembramos que o resultado da abordagem da educação ambiental crítica nos trabalhos de pesquisa da área também é discutido por Carvalho (2016, p.154) quando afirma que:

[...] diretamente associado às questões relativas aos referenciais teóricometodológicos das pesquisas no campo da EA, os textos dos GDPs reconhecem a adesão, por parte de muitos dos investigadores do campo, às acepções que associam EA com interpretações da realidade entendidas como críticas. [...].

Contudo, o autor ressalta a importância de análises mais criteriosas, para que evitemos os "falsos consensos construídos a partir de nossas práticas discursivas" (CARVALHO, 2016, p.154). Para ele é,

[...] necessário o cuidado para não alimentarmos a falsa ideia de que as perspectivas crítica e emancipatória estão se fazendo presentes em nossos textos sem conflitos, controvérsias ou lutas político-ideológicas, na busca por conquista de espaços hegemônicos no campo da pesquisa em educação ambiental (CARVALHO, 2016, p.155).

Nossa discussão acrescenta ao debate uma preocupação, com a prática social da pesquisa em educação ambiental, quanto a criação de uma conjuntura que articule as perspectivas teóricas e metodológicas de modo coerente nas pesquisas. Temos observado que, como são mobilizadas diferentes referências e de diferentes áreas para a construção da pesquisa, nem sempre os autores têm uma coerência epistemológica vinculada aos pressupostos críticos. Nesse sentido, nossas análises buscam caracterizar questionamentos que têm preenchido as discussões nos GDP dos EPEA.

\section{A pesquisa em educação ambiental como prática social e a dinâmica realizada no GDP do IX EPEA numerar seção}

Uma prática social que surge ancorada na militância e/ou compromisso social da pesquisa. O campo da pesquisa em EA tem sido caracterizado como plural e heterogêneo, desde sua formação, a partir do campo ambiental e da educação. Esta pluralidade proporciona que o objeto de pesquisa seja entendido a partir de diferentes referenciais. Considerando que neste artigo analisamos os textos submetidos ao GDP de formação do IX EPEA, neste item relatamos a dinâmica realizada durante os debates presenciais no GDP. Em nosso relatório, apresentado ao final do evento, informamos um conjunto de procedimentos que, em nosso entendimento, atendiam à tendência proposta de politização das ações do GDP, como denúncia e anúncio de uma proposta política, no contexto da dialógica (FREIRE, 1983).

Com esse propósito e intenção, combinamos conjuntamente, realizar um trabalho numa perspectiva mais dialogal. Para isso, nosso propósito foi viabilizar ao grupo uma interlocução em torno do conceito de Formação e o tema central do IX EPEA: Pesquisa em Educação Ambiental: Democracia, Políticas Públicas e Práticas Educativas. Com o Círculo Dialógico potencializado por esse tema gerador, nosso principal objetivo foi gerar uma agenda de pesquisa atravessada por essas questões contemporâneas. Partimos da premissa de que é urgente integrar uma proposta de pesquisa e formação, pesquisa em formação e pesquisa para a formação, mobilizadas por uma tomada de consciência do contexto sociopolítico, enquanto instância essencial na/da formação.

Pudemos observar que as pesquisas relacionadas a esse GDP e apresentadas no IX EPEA, em certa medida, apresentavam a necessidade de maior amadurecimento teóricoconceitual, quanto à criticidade política do fazer educativo/formativo, que pudesse ter em foco a característica estrutural da política, enquanto parte constitutiva e constituinte da formação, da pesquisa como processo formativo e da pesquisa no âmbito da formação. 
Começamos as atividades do grupo dialógico, então, com a apresentação da proposta de que cada pessoa faria um parágrafo, apresentando seu entendimento de formação, relacionando com os conceitos de base do tema central do IX EPEA. Em seguida, abrimos para uma roda de conversa - entenda-se um Círculo Dialógico - nos moldes freireanos, apresentando a produção do grupo.

Nosso círculo dialógico, nos moldes de Paulo Freire, se emoldurou pela constituição de um grupo aprendente no formato circular, em que cada pessoa tinha a percepção das outras pessoas que constituem com ela o grupo. Há um foco naquele(a) que fala e a escuta acontece de maneira amorosa, em busca de consensos e ampliação do campo perceptivo e de compreensão parceira. Um tema atua como dispositivo propulsor do diálogo. O diálogo é horizontal e mediado pela intencionalidade de contemplar os princípios dialogais: a amorosidade, a humildade de reconhecer o quanto ainda tem a aprender, o esperançar de momentos melhores, a fé no ser mais, a criticidade enquanto desvelar da razão de ser. A Teoria Freireana inspira a ideia de temas que alavanquem transformações sociais.

Cada pessoa tinha, então, a oportunidade de expor sua tessitura e o grupo participava problematizando, contribuindo com a ideia, ampliando a reflexão proposta inicialmente pelo autor do textinho. Finalizamos o trabalho com o exercício do abraço de verdade, ou seja, sugerimos que escolhessem alguém que ainda não conheciam até hoje e dessem um abraço de, no mínimo, trinta segundos. Isso amplia o entendimento na direção de um corpo consciente, de um corpo de relações, de um corpo amoroso. Insere outras dimensões no ato de conhecer.

Avaliando suscintamente essa tessitura coletiva, fruto desse movimento de parceria e cooperação, constatou-se um viés muito associado ao entendimento dos limites da formação, diante desse quadro atual e, particularmente, diante de uma democracia que não nos representa e de um projeto político individualista e muito pautado pela formação institucional, imposta de cima para baixo, e proposta de uma maneira artificial e dissociada do ambiente a que se destina, desconhecedora do grupo ao qual é proposta, em geral. Portanto, pudemos constatar que tivemos um panorama dos limites das práticas formadoras atuais e que emergem das pesquisas que se detiveram a observar essas questões.

No segundo dia, nós começamos com a mesma dinâmica proposta no fechamento do dia anterior. Entretanto, nesse caso detalhamos melhor o objetivo dessa atividade. Falamos que a formação, em geral, desconsidera outras dimensões essenciais no processo, ao deixar de lado o corpo, as emoções, sentimentos etc. Praticamente, a carga de tarefas formadoras se detém no cognitivo, numa abordagem meramente pragmática.

$\mathrm{Na}$ sequência, foi proposto que fizessem um novo texto, agora com a ideia geradora pautada por experiências exitosas de formação que eles viveram, experienciaram em sua formação, em pesquisas que realizaram ou em situações observadas. Diante disso, cada pessoa apresentava e, novamente, tínhamos a interação do grupo com as apresentações que adquiriam com isso um caráter mais coletivo e parceiro.

Nessa conjuntura, tivemos a oportunidade de perceber alguns pontos interessantes. Um deles destacado durante o Círculo Dialógico. Esse fator que emergiu quase que imediatamente durante as falas, diz respeito ao detalhe que a maioria das experiências de sucesso apresentadas estavam, de algum modo, ligadas às outras dimensões semióticas. Melhor dizendo, a maioria das narrativas formadoras apresentavam práticas formadoras que utilizaram meios que tocavam dimensões habitualmente desconsideradas nas práticas pedagógicas, tais como trilhas sensório-interpretativas, análise de imagens, interpretação semiótica de vídeos, conviver com ambientes distintos da vida cotidiana, imersão noutras culturas, a consideração por aspectos ético-estéticos etc. Esse aspecto da formação contempla outras lógicas e pode gerar comprometimento social. 
Fechamos o parêntese da anunciação das experiências vividas durante o IX EPEA e retomamos o texto em torno de nossa definição teórico-conceitual, de nossas referências ainda por ampliar.

Cada vez mais, nos parece que democracia é conceito a ser revisado e que democracia representativa, comumente, não representa aqueles(as) que deviam ser representados(as) por esses(as) representantes que apenas se representam. As práticas sociais e educativas corroboram com essa matriz antidemocrática, ou falsamente democrática (FIGUEIREDO, 2018). Em nossa dialogaçãofreireana: "Não tememos apontar a nossa 'inexperiência democrática', responsável por tantas manifestações de nosso comportamento, como a matiz desta educação desvinculada da vida, autoritariamente verbal e falsamente humanista, em que nos desnutrimos" (FREIRE, 1959, p. 12).

Numa outra direção, Paulo Freire nos inspira na busca de procedimentos que favoreçam uma real democracia. E essa, passa necessariamente pelo diálogo, que segundo ele é uma das matrizes da democracia. Ele também salienta que: "Não há democracia sem povo participante". (PAULO FREIRE, 1959). E isso nos remete a uma democracia participativa, essa sim, amplamente democrática.

\section{Considerações finais: pactuando uma agenda de pesquisa para o GPD de formação de professores/educadores}

Entender aspectos discursivos da pesquisa em educação ambiental, a partir dos textos do GDP de formação, permitiu caracterizar questões que podem ser exploradas tanto do ponto de vista teórico-prático como prático-teórico para avançar nas pesquisas. Nesse sentido, ainda temos um caminho por construir no sentido de entender que referenciais teóricos estão constituindo as pesquisas no campo. Observamos a necessidade de avançar na discussão sobre Estado Democrático e participação nos processos de tomada de decisão, frente às questões ambientais, tendo em vista políticas recentes, que têm sido propostas/impostas, que descaracterizam processos democráticos e privilegiam interesses privados e de mercado, tanto na educação quanto nas questões ambientais.

Também, a partir deste estudo, entendemos que a pesquisa engajada está presente nas preocupações e motivações dos pesquisadores do GDP. Isso gera cenários empíricos diversos para análise das práticas educativas, em geral provindas de contextos locais. Além disso, observamos nesse GPD que as políticas públicas têm representado uma fonte de problematização, de questões, por sua vez, gerando pautas de novas pesquisas. Nesse sentido, os pesquisadores relatam pesquisas nas quais políticas públicas de EA e/ou em educação e/ou ambientais são questionadas e ressignificadas.

Para pensar em uma agenda de pesquisa para o GDP, nos arriscamos a formular possíveis caminhos a partir dos sentidos que fomos reconhecendo nos diálogos com os trabalhos do GDP:

- Refletir sobre os impactos de mudanças recentes nas políticas educativas sobre a formação do professor/educador ambiental. Pensar como a prática educativa, como componente curricular por exemplo, seria um espaço fértil para o aprimoramento da EA na formação inicial. Refletir sobre críticas que podem ser feitas às políticas como "Escola sem partido, Base Nacional Comum Curricular e seus impactos na formação docente?

- Investigar os currículos de formação inicial de modo a entender espaços/lugares alternativos de formação do professor/educador ambiental que extrapolam os espaços disciplinares.

- Avançar nas discussões sobre a identidade do professor/educador ambiental, a partir da noção de identidades fragmentadas, formuladas pela noção de mundo que considera 
mecanismos mais fluidos de entendimento da relação espaço e tempo. Nesse sentido, como entender o educador ambiental a partir de várias identidades, algumas vezes contraditórias ou não resolvidas, e que assumem identidades diferentes em diferentes momentos? Como tais identidades dialogam com as políticas públicas de formação docente e com a própria Política Nacional de Educação Ambiental?

- Ampliar o diálogo com a comunidade internacional sem sucumbir aos processos de colonialização, orientados por visões eurocêntricas da produção do conhecimento científico e da educação ambiental.

Por fim, salientamos a importância dos estudos tipo estado da arte para entender o campo da pesquisa em EA e seus limites, e consideramos que os temas do campo que não aparecem nesse GDP podem estar presentes em outros GDP, na percepção de que a formação pode se manifestar de outras formatações.

Esperamos que nosso trabalho, nesse GDP, possa resultar em pautas de pesquisa mais comprometidas e engajadas com esse mundo melhor que desejamos. Que possamos ter esse mundo, como disse Paulo Freire, onde seja, de fato, possível amar.

\section{Referências}

BRASIL. MINISTÉRIO DA EDUCAÇÃO. Parâmetros curriculares nacionais: Brasília (DF), 1997.

BRASIL. Ministério da Educação. Base Nacional Comum Curricular. Proposta preliminar. Segunda versão revista. Brasília: MEC, 2016. Disponível em: <http://basenacionalcomum.mec. gov.br/documentos/bncc-2versao.revista.pdf>. Acesso em: 23 mar. 2017.

CARVAlHO, L. M. Demandas e agendas da Pesquisa em educação ambiental no Brasil: Sentidos Construídos a partir dos relatos dos Grupos de Discussão de Pesquisa em Educação Ambiental (GDPS -EPEAS). Pesquisa em Educação Ambiental, Rio Claro, v.11, n.2. p. 146-167, 2016.

CHOULIARAKI, L.; FAIRCLOUGH, N. Discourse in late modernity: rethinking Critical Discourse Analysis. Edinbourg: EdinbourgUniversity, 1999.

ENCONTRO DE PESQUISA EM EDUCAÇÃO AMBIENTAL - EPEA. [Online].Juiz de Fora: UFJF, 2017. Disponível em: <https://nonoepea.webnode.com/sobre-o-evento/>. Acesso em: 2 jun. 2018.

FAIRCLOUGH, N. Analysing discourse: textual analysis for social research. London/New York: Routledge, 2003.

FARIAS, L.A.; MARTORANO. S.A.A. O desafio das questões etnicorraciais e a educação ambiental na formação de professores: um estudo de caso. In: ENCONTRO DE PESQUISA EM EDUCAÇÃO AMBIENTAL, 9, 2017, Juiz de Fora. Anais... Juiz de Fora: UFJF, p.1-8 ,2017.Disponível em: <http://epea.tmp.br/epea2017_anais/pdfs/plenary/0051.pdf>Acesso em: 2 jun. 2018.

FERREIRA, A. B. de H.Novo Dicionário Aurélio: Século XXI Eletrônico [Cd Room]. Rio de Janeiro, RJ: Nova Fronteira, 1999.

FIGUEIREDO, J. B. A. Epistemologias Populares e a Decolonialidade do saber no contexto das Políticas Públicas. In: REUNIÃO ANUAL DA ASSOCIAÇÃO NACIONAL DE PÓSGRADUAÇÃO E PESQUISA EM EDUCAÇÃO, 33, 2010, Caxambu. Anais...Cd. Caxambu: ANPED, 2010.

FIGUEIREDO, J. B. A.Paulo Freire e sua leitura crítica e nordestina do Brasil. In: BARCELOS, Valdo (Org.). Interpretes do Brasil: ontem e hoje. Santa Maria: Ed. e Gráfica Curso Caxias, 2018. 
FREIRE, P.Educação e atualidade brasileira. Portal Paulo Freire. [Online]. Recife: Universidade Federal do Recife, 139p. (tese de concurso público para a cadeira de História e Filosofia da Educação de Belas Artes de Pernambuco). Recife, Pe: Universidade Federal de Pernambuco, 1959.Disponível em: 〈http://www.acervo.paulofreire.org:8080/jspui/handle/7891/1976>. Acesso em: 2 jun. 2018.

FREIRE, P.Pedagogia do oprimido. 13 ed. Rio de Janeiro: Paz e Terra, 1983.

FREIRE, L.; FIGUEIREDO, J. B. A.; GUIMARÃES, M. O papel dos professores/educadores ambientais e seus espaços de formação. Qual é a educação ambiental que nos emancipa? Pesquisa em Educação Ambiental (Online), v. 11, p. 117-125, 2016.

GARRIDO, L.S.; MEIRELLES, R.M.S. Educação Ambiental na formação Docente: o que discutir? In: ENCONTRO DE PESQUISA EM EDUCAÇÃO AMBIENTAL, 9, 2017, Juiz de Fora. Anais... Juiz de Fora: UFJF, p.1-11, $2017 . \quad$ Disponível em:<http://epea.tmp.br/epea2017_anais/pdfs/plenary/0085.pdf>.Acesso em: 2 jun. 2018.

GUARESCHI, N.; COMUNELlO, L.N.; NARDINI, M.; HOENISCH, J.C. Problematizando as práticas psicológicas no modo de entender a violência. In: STREY, Marlene N.; AZAMBUJA, Mariana P. Ruwer; JAEGER, Fernanda Pires (Orgs.). Violência, gênero e Políticas Públicas. Porto Alegre, RS: Ed. EDIPUCRS, 2004.

LOUREIRO, C. F. B.; CUNHA, C.C. Educação ambiental e gestão participativa de unidades de conservação: elementos para se pensar a sustentabilidade democrática. Ambiente \& Sociedade, Campinas, v. 11, n. 2, p. 237-253, jul./dez. 2008.

MATURANA, R. H.Democracia es una obra de arte. Colombia: Cooperativa Editorial Magisterio/ Instituto para el Desarrollo de la Democracia Luis Carlos Galán, 1993.

MATURANA, R. H.Emoções e linguagem na educação e na política. Trad. José Fernandes C. Forte. Belo Horizonte: Ed. da UFMG, 1998.

NOTALGIACOMO, E.A.; CARVALHO, M.B.S.S. O currículo paulista e as abordagens da relação homem natureza. In: ENCONTRO DE PESQUISA EM EDUCAÇÃO AMBIENTAL, 9, 2017, Juiz de Fora. Anais...Juiz de Fora: UFJF, p.1-8, 2017. Disponível em:<http://epea.tmp.br/epea2017_anais/pdfs/plenary/0239.pdf>.Acesso em: 2 jun. 2018.

PEREIRA, R. C. M; BASILIO, R.; LEITÃO, P.D.V. Artigo científico: um gênero textual caleidoscópico. DELTA, São Paulo, v. 33, n. 3, p. 663-695, Sept. 2017.

RAMALHO, V.; RESENDE, V. M. Análise de discurso (para a) crítica: O texto como material de pesquisa. Campinas: Pontes Editores, 2011. (Coleção: Linguagem e Sociedade Vol. 1).

SOUZA-SANTOS, B.A gramática do tempo: para uma nova cultura política. 2 ed. São Paulo: Cortez, 2008. (Coleção para um novo senso comum Vol. 4).

SOUZA-SANTOS, B. Epistemologías del Sur. Utopía y Praxis Latinoamericana.Maracaibo, Estado Zulia, Venezuela,v.1., n.16, p.17-39, 2011. 